\title{
Intermediate Lipomatous Neoplasm
}

National Cancer Institute

\section{Source}

National Cancer Institute. Intermediate Lipomatous Neoplasm. NCI Thesaurus. Code C7630.

A lipomatous neoplasm characterized by a high risk of local recurrence and no risk of metastasis. 